\title{
Genomic and template RNA transcription in a model of persistent enteroviral infection
}

\author{
JW Gow ${ }^{1}$, WMH Behan ${ }^{2}, \mathrm{P}_{\text {Cash }}^{3}$, K Simpson ${ }^{1}$ and PO Behan ${ }^{1}$ \\ Departments of ${ }^{1}$ Neurology and ${ }^{2}$ Pathology, Glasgow University, Glasgow, UK; ${ }^{3}$ Department of Medical Microbiology, \\ Aberdeen University, Aberdeen, UK
}

\begin{abstract}
Enteroviruses have been implicated in persistent infections of the nervous system and in certain paralytic motor neurone syndromes. Enteroviral persistence may depend on defective transcription, resulting in the abnormal production of equal amounts of genomic and template RNA strands rather than the normal ratio of $60-100: 1$. An in vitro model of a persistent coxsackie virus in human skeletal muscle cells was investigated using in situ hybridisation and a semiquantitative parallel, complementary, reverse transcriptase polymerase chain reaction. The ratio of genomic to template RNA was found to be approximately $60: 1$. We conclude that enteroviral persistence in this in vitro model is not dependent on altered transcription. In vivo, other viral and host factors should be considered.
\end{abstract}

Keywords: RNA transcription; persistent enterovirus; viral replication

The concept that persistent viral infections may play a role in central nervous system (CNS) diseases of unknown aetiology, is important. Viral persistence depends on two components: an ineffective immune response in the host and an altered replication strategy in the virus (Oldstone et al, 1982). The infected cells may show no evidence of damage but gross disturbance of their differentiated function. This pattern of disease is particularly relevant in considering CNS diseases which involve neurotransmitter deficiencies. Indeed Lipkin et al (1988) have shown that neonatal mice infected with lymphocytic choriomeningitis virus (LCMV) show reduced production of the neurotransmitter, somatostatin, by virally-infected neurones. In vitro models confirm these effects with normal-appearing but infected cells showing normal growth and cloning rates associated with lack of neurohormonal production (Oldstone, 1991).

Coxsackie viruses, members of the family Picornaviridae, are important human pathogens, usually causing acute, self-limited infections but occassionally producing chronic disease e.g. chronic myocarditis. (Woodruff, 1980; Kandolf and Hofschneider, 1989). In the last decade, there have been several reports suggesting that persistent enteroviruses may be the cause of various CNS and muscle disorders of unknown aetiology, including motor neurone disease (Martyn et al, 1988; Woodall et al,

Correspondence: WMH Behan

Received 8 August 1996; revised 25 September 1996; accepted 5 November 1996
1994), the post-polio syndrome (Sharief et al, 1991; Dalakas, 1995), the chronic fatigue syndrome (Archard et al, 1988; Behan and Behan, 1988; Gow et al, 1991) the autoimmune myopathies (Bowles et al, 1987; Behan and Behan, 1993) and the cardiomyopathies, especially dilated cardiomyopathy (DCM) (Bowles et al, 1986; Kandolf and Hofschneider, 1989; Tracy et al, 1990; Klingel et al, 1992). The evidence has been based on serological findings and the detection of enteroviral genomes in the affected tissues: in no case has infectious virus been isolated.

The mechanism which allows viral persistence is not known but mutation is likely to be involved (Matloubian et al, 1990; Salvato et al, 1991). Enteroviruses mutate frequently and, in vitro, persistent strains have been shown to emerge, with reduced lytic effects and changes in cell tropism (Pelletier et al, 1991). Human and animal studies in myocarditis and the chronic fatigue syndrome have suggested that persistent enterovirus shows a defective replication pattern at the level of transcription (Kandolf and Hofschneider, 1989; Cunningham et al, 1990; Hohenadl et al, 1991).

The coxsackie virus genome is a single-stranded coding sequence RNA molecule of about 7400 nucleotides in length (Tracy, 1988). The plus strand genomic RNA molecule functions as messenger RNA for the synthesis of virus proteins and also as the template for a complementary, non-coding minus strand. During the replication cycle in the usual acute cytolytic infection, the ratio of plus to minus strand RNA synthesised, is approximately 100:1 (Kandolf et al, 1991). This asymmetrical 
synthesis reflects the requirement for each strand in the life cycle of the virus: the plus strand encodes the viral proteins and is also packaged into new virions for release into the infected cell while the minus strand functions as the template for the production of new plus strand RNA genomes (Tracy, 1988). Thus symmetrical synthesis of plus and minus strands would result in severely reduced viral replication and could explain the failure to isolate infectious virus from affected cases; reactivation and disease progression would require reversion to the normal replication pattern (Kandolf and Hofschneider, 1989; Cunningham et al, 1990).

An in vitro carrier cell model of a persistent coxsackie B5 (CVB5) infection has been developed recently in a muscle (rhabdomyosarcoma, RD) cell line (Argo et al, 1992; McLaren et al, 1993). The virus produces no detectable cytopathic effect (cpe) and cellular protein synthesis appears to be inhibited. It has now been maintained for more than 100 passages in our laboratories (McLaren et al, 1993 and Gow JW, unpublished data). We report here an analysis of the replication of this coxsackie virus, using in situ hybridisation and a semiquantitative parallel complementary reverse transcriptase polymerase chain reaction (RT-PCR) which was developed to examine the ratios of genomic positive (plus) to template negative (minus) viral strands (Gow et al, 1995). The results were compared to those found in acute coxsackie B5 virus infections of RD and HEp2 cell cultures.

Rhabdomyosarcoma (RD) cells were obtained from ICN-Flow (High Wycombe, UK) and maintained in minimal Eagles medium (MEM) supplemented with $2 \%$ foetal calf serum (FCS). The origin of the coxsackie B5 virus (CBV5) isolate 3673 (CBV3673) has been described previously (Cash, 1991; Argo et al, 1992). Two of the virus intracellular proteins, p33 and p39, show mutations which have increased their basic charges and reduced their molecular weights (McLaren et al, 1993). Virus stocks were prepared and titred in HEp2 cells.

Persistently infected RD carrier culture (piRD3673) cells were obtained by infecting RD cell monolayers, prepared in $25 \mathrm{~cm}^{2}$ tissue culture flasks, with CBV-3673 at approximately $10^{5.8} \mathrm{TCD}_{50}$ virus per $3 \times 10^{6} \mathrm{RD}$ cells as described (McLaren et al, 1993). Virus-infected cells, together with control uninfected RD cell monolayers, were covered with MEM supplemented with $2 \%$ FCS and incubated at $37^{\circ} \mathrm{C}$ for 4 days. No virus-induced cytopathic effect (cpe) was observed. Cells were then cultured at a split ratio of $1: 3$ and subcultured at $3-4$ day intervals. To determine the titre of infectious virus, the piRD cell monolayer was disrupted by freezethawing. The combined cell lysate and culture medium was then assayed for infectious virus using the micro-titration assay.

RNA was prepared from $1 \times 10^{7}$ tissue culture cells and from $2 \mathrm{~mm}^{3}$ muscle biopsy samples using the acid-guanidium-phenol-chloroform (AGPC) method (Chomczynski and Sacchi, 1987). The quality of the RNA was determined by agarose gel electrophoresis and examination of the $28 \mathrm{~S}$ and $18 \mathrm{~S}$ RNA bands; and by amplification of a housekeeping gene, ableson tyrosine kinase (Gow et al, 1991).

Synthetic oligonucleotide primers which had been tested previously on a wide range of enteroviral serotypes were used in this study (Gow et al, 1991; Zoll et al, 1992). They were custom synthesised by Genosys (Cambridge, UK).

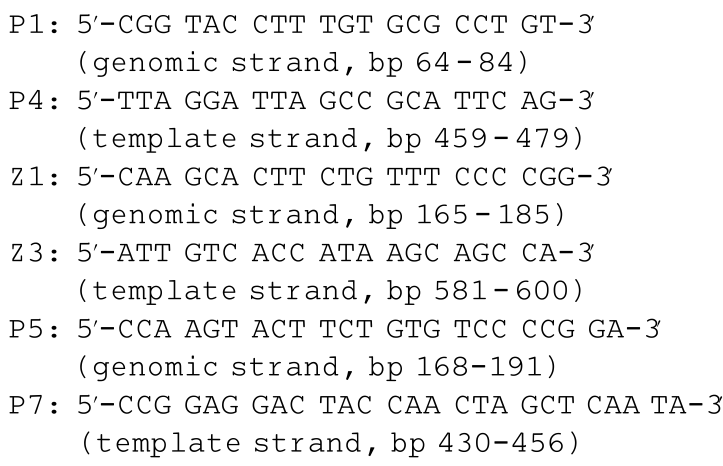

To examine the relative amounts of viral RNA and to ensure that preferential primer/nucleic acid binding of any oligonucleotide did not give rise to an incorrect result, cDNA synthesis and PCR were carried out using three different sets of oligonucleotides. The sets were:

Set 1: genomic cDNA synthesised with $\mathrm{P} 4$ followed by RT-PCR with PCR primers, P5 and P7; template cDNA synthesised with P1 followed by RT-PCR with primers, P5 and P7

Set 2: genomic cDNA synthesised with Z3 followed by RT-PCR with primers, Z1 and P7; template cDNA synthesised with Z1 followed by RT-PCR with primers, $\mathrm{Z} 1$ and $\mathrm{P} 7$

Set 3: genomic cDNA synthesised with Z3 followed by RT-PCR with primers, Z1 and P4; template cDNA synthesised with P1 followed by RT-PCR with primers, $\mathrm{Z} 1$ and $\mathrm{P} 4$

In situ enterovirus-specific complementary oligonucleotides hybridisation probes were used in parallel experiments over the same time course. Sequences were as follows:

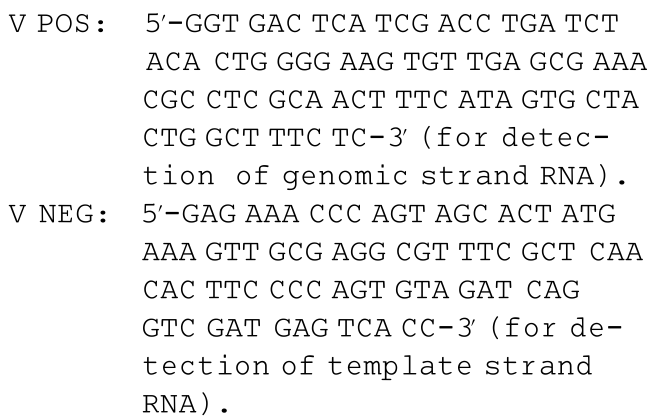


For analysis of replication, a semiquantitative parallel complementary RT-PCR of plus and minus viral RNA strands was used. This technique has been described in detail recently (Gow et al, 1995) and is illustrated in Figure 1. Briefly, a standard cDNA synthesis was used to synthesise either coding (genomic, plus) or non-coding (template, minus) enteroviral strands. Equal aliquots of RNA $(1 \mu \mathrm{g})$ were copied into cDNA using 200 units of (MMLV) reverse transcriptase (BRL) and $0.5 \mu \mathrm{g}$ of either the oligonucleotide coding for the plus strand e.g. P1 or for the minus strand e.g. P4 of CVB5. The two parallel complementary first strand cDNA populations obtained were then amplified separately in a nested PCR reaction, using nested oligonucleotide primer sets. Thirty-five cycles of amplification were carried out, each cycle consisting of $94^{\circ} \mathrm{C}$ for $1 \mathrm{~min}, 55^{\circ} \mathrm{C}$ for $1 \mathrm{~min}$ and $72^{\circ} \mathrm{C}$ for 1.2 min. Titration experiments were performed to ensure that the reaction had not gone to completion by exhaustion of the dNTPs, PCR primers or Taq

\section{Parallel Complementary RT-PCR for Genomic and Template Viral Strands}

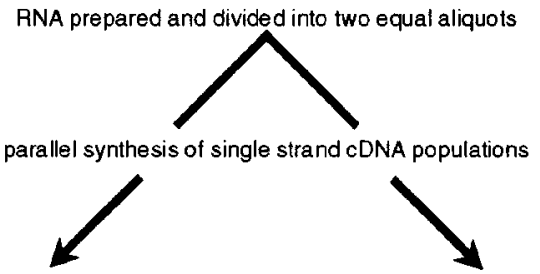

$\mathrm{RNA}+$ minus strand primer + RT

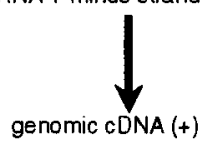

paral

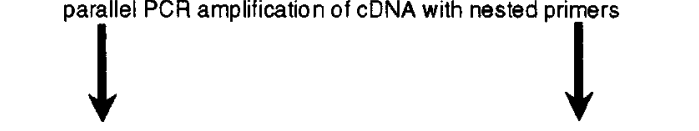

genomic (+) PCR products

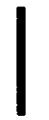

template (-) PCR products

agarose gel electrophoresis, ethidium bromide stain

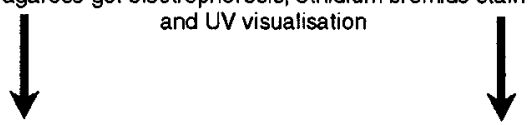

estimate of genomic (+) RNA strands estimate of template (-) RNA strands

Figure 1 Outline of the parallel complementary RT-PCR method for the analysis of genomic and template viral strands. Two populations of cDNA are synthesised from aliquots of RNA, using either a plus or a minus strand primer. PCR is then performed separately on the two cDNA populations, using nested PCR primers. The products are visualised on ethidium bromide-stained agarose gels. polymerase enzyme. PCR products were electrophoresed through a $2.0 \%$ agarose gels in $1 \times \mathrm{TBE}$ buffer, stained with ethidium bromide and visualised under ultraviolet illumination.

For in situ hybridisation piRD-3673 cells were cultured on RNAse-free, poly-L-lysine coated cover slips in multiwell tissue-culture plates, in MEM containing $5 \%$ foetal calf serum for $24 \mathrm{~h}$. Cells were then washed in PBS and fixed in $4 \%$ paraformaldehyde for $1 \mathrm{~h}$ at $4^{\circ} \mathrm{C}$. Cytospin preparations of the cultured cells were then examined by in situ hybridisation (Farquharson et al, 1990; Hillan, 1990). Coverslips were attached to glass slides with GlassBond prior to the in situ procedure. Digoxygenin-labelled oligonucleotide probes, V POS and V NEG, specific for the positive strand and negative strands of viral RNA respectively (see above) were obtained from Genosys, Cambridge, UK. Uninfected RD cells were used as a negative control and CVB5infected HEp2 cells as a positive control.

The semiquantitative parallel complementary RT-PCR demonstrated that the ratio of plus (genomic) to minus (template) RNA in the piRD-3673 cell cultures was approximately 60:1 on densitometry (not shown). The range for several experiments was 48 to $68: 1$, with the mean being $60: 1$. Three primer sets had been selected to make sure that any nonspecific, preferential binding of oligonucleotides could be detected.

In Figure 2, the results of taking samples for electrophoresis from the reaction mixtures at cycles $15,20,25$ and 35 are shown. The results from the

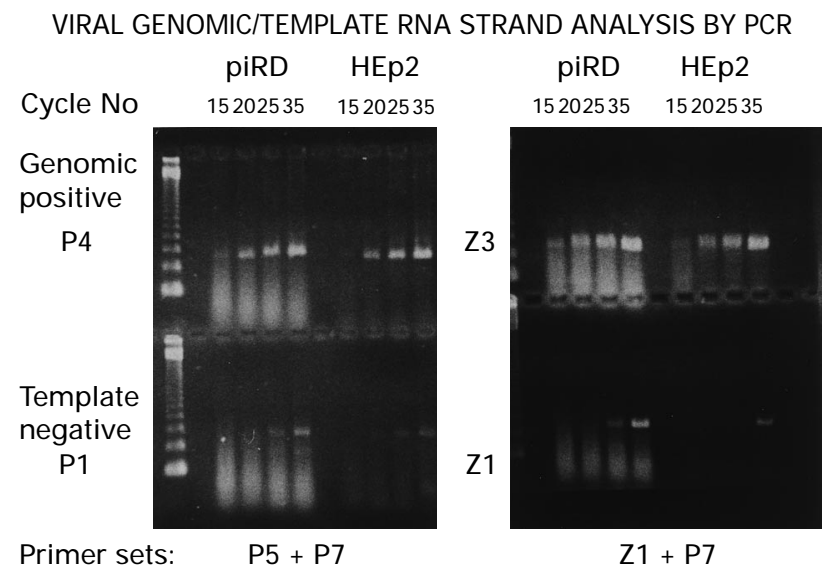

Figure 2 Analysis of acutely (HEp2) and persistently (piRD) infected cells by parallel complementary RT-PCR. CDNA populations were synthesised from RNA aliquots isolated from infected cells using primers $\mathrm{P} 4$ or Z3 (for genomic cDNA) or primers P1 or Z1 (for template CDNA). PCR was then carried out using nested primer sets $\mathrm{P} 5+\mathrm{P} 7$ (for the $\mathrm{P} 4$ and $\mathrm{P} 1$ cDNAs) or $\mathrm{Z} 1+\mathrm{P} 7$ (for the Z3 and Z1 cDNAs). Aliquots $(20 \mu \mathrm{l})$ of the PCR reactions removed at 15,20,25 and 35 amplification cycles and electrophoresed through ethidium-bromide stained $2 \%$ agarose gels were visualised under ultraviolet light. The size marker was the BRL $123 \mathrm{bp}$ ladder. Enterovirus PCR products were $289 \mathrm{bp}$ (P5-P7) and 286 bp (Z1-P7). 
piRD cells are compared to those from CVB5infected HEp2 cells, using two of the primer sets. The plus strand cDNA was synthesised using P4 or Z3 (minus strand primers) and the minus strand by P1 or Z1 (plus strand primers). It can be seen that genomic PCR products were readily detected at 15 cycles in both cell cultures, whereas template PCR products are only just visible at 25 cycles. Thus there was an obviously increased ratio of genomic to template viral material in the persistently infected carrier cell culture, similar to that in the acutely infected control cells.

In the in situ hybridisation studies, the genomic strand probe revealed a strong hybridisation signal in $3 \%$ of the piRD-3673 cells (Figure 3 ). No necrotic cells were seen, unlike in the acutely infected HEp2 cell cultures. In the latter, signal was detectable in more than $70 \%$ of cells (not shown). In the individual $\mathrm{RD}$ or HEp2 cells which were positive, the appearance of the signal was the same i.e. a dense mass occupying most of the cytoplasm. As regards the template strand probe, this was detectable with difficulty as a very faint brown signal, again in approximately $3 \%$ of the piRD cells (not shown). No signal was detected in the negative control of uninfected HEp2 cells hybridised with a non-viral plasmid vector.

Enteroviruses usually cause acute lytic infections but there is no doubt that they can be responsible for persistent infection of the nervous system. In mice, Theiler's virus causes persistent infection accompanied by primary demyelination (Cash et al, 1988) while in immunosuppressed patients, chronic meningoencephalitis and poliomyelitis may occur (Wilfert et al, 1977; Davis et al, 1977; Webster et al, 1993; McKinney et al, 1987). A role for enteroviruses has been postulated in the post-polio syndrome (Sharief et al, 1991) and in motor neurone

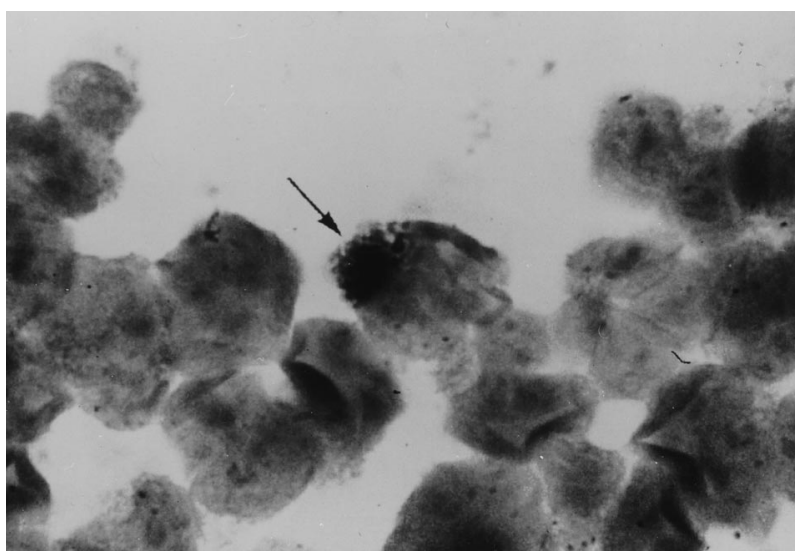

Figure 3 In situ hybridisation, magnification $\times 1000$. Using the VPOS (genomic) digoxygenin-labelled oligonucleotide probe, obvious genomic signal is seen in the cell cytoplasm of an infected piRD cell. disease (Martyn et al, 1988; Woodall et al, 1994) although, as discussed by Dalakas (1995) in the latest review, these findings have not been confirmed.

Persistent viral infections have attracted a great deal of interest since Oldstone et al (1982) and Oldstone (1991) showed convincingly that there is a particular pattern of damage in persistent, as opposed to acute, infections: namely, no histological signs of cell death or inflammation in the tissue affected but interference in cell function. $\mathrm{He}$ suggested that dysfunction in differentiated cells, in the absence of cell damage, is the hallmark of a persistent viral infection. This is of obvious interest in trying to establish the aetiology of several disorders of the central nervous system in which there is deficient production of neuro-hormones or neurotransmitters in the absence of any signs of cell damage. Indeed, Oldstone and his colleagues have already shown that in mice infected at birth with LCMV, apparently normal pituitary cells are virally infected and produce no hormones while normalappearing neurones fail to secrete somatostatin (Oldstone, 1991; Lipkin et al, 1988).

The mechanism of persistence is unknown but studies of LCMV have shown that it is likely to be related to mutation (Matloubian et al, 1990; Salvato et al, 1991). Enteroviruses mutate frequently and a change in a single nucleotide in the $5^{\prime}$ nontranslated region (NTR) of the poliovirus, for instance, can cause a dramatic change in virulence (Evans et al, 1985; Pelletier et al, 1991). Mutant polioviruses will establish persistence in vitro, associated with a reduced lytic effect and a change in cell tropism (Pelletier et al, 1991). Mutant Theiler's virus can persist in glioma cell lines and then fail to induce demyelination in the usual mouse model (Patrick et al, 1990). Similarly, a chimeric Theiler's virus may show altered cell tropism (Jarousse et al, 1994).

Many workers have reported that enteroviruses can establish persistence easily in vitro (Martino et al, 1995; Borzakian et al, 1992; McLaren et al, 1993). When they do, they produce carrier cell cultures (Schnurr and Schmidt, 1989) in which there is detectable viral genome or antigen in $2-10 \%$ of the cells (Borzakian et al, 1992; McLaren et al, 1993) associated with a reduced lytic potential. The release of enterovirus, however, may not depend on cell lysis (Martino et al, 1995) so that a persistent infection can be established by a non-lytic method of spread. The focal nature of the persistent infection in vitro in this carrier cell culture is similar to the picture of chronic myocarditis in vivo, where foci of infected myocytes amongst uninfected fibres are a striking feature (Kandolf et al, 1991).

The in vitro model used here was established in RD cells which are immortalised cells derived from an embryonal rhabdomyosarcoma (McAllister et al, 1969). Myoglobin and myosin ATPase are readily 
detectable although only occasional myofibrils are found. Wild-type coxsackie B virus, however, will cause a cpe in the cell culture, indicating that the cell receptors for virus are unchanged. The effects on cell metabolism of persistent enteroviral infection have not yet been determined but are now under investigation. They may be difficult to detect, since only a small proportion of cells are involved and the majority could mask any virus-induced alterations. However, it will be important to establish whether or not persistent enteroviruses have similar effects to LCMV.

Our model of enteroviral persistence is similar to those reported by others, the virus having been passaged more than 100 times without any cpe or inhibition of cellular protein synthesis. The altered electrophoretic mobility of two virus proteins, p39 and p33, confirms that mutations have occurred (McLaren et al, 1993). Mutations in p39 and p33, as well as in VP1, have also been observed in coxsackie B virus released from persistently infected lymphoid-derived cell lines (D Amarasekera, HB Gimenez, E Argo and P Cash, submitted for publication). Although the biological effects of these protein mutations are not yet known, they could influence virus replication and maturation of the virion, leading to disruption in the normal process of virus infection and permitting the development of a persistent coxsackie B virus infection.

Kandolf and co-workers studied the possible mechanisms of persistence extensively in a murine model of enteroviral myocarditis after Cash et al (1988) originally reported restricted replication in Theiler's virus infection. The latter workers developed single-stranded RNA probes for strand-specific detection of enteroviral RNA in order to analyse replication. It was found that, while positive strands were produced in great excess compared to negative strands in the acute phase, in the second, persistent, phase, the amounts of positive and negative strand RNA were equal in the same infected myocardial cells (Hohenadl et al, 1991; Kandolf et al, 1991; Klingel et al, 1992). It was concluded that a defective virus had established persistence and that

\section{References}

Archard LC, Bowles NE, Behan PO, Bell EJ, Doyle DJ (1988). Postviral fatigue syndrome: persistence of enterovirus RNA in muscle and elevated creatine kinase. J Roy Soc Med 81: 326-329.

Argo E, Gimenez B, Cash P (1992). Non-cytopathic infection of rhabdomyosarcoma cells by coxsackie B5 virus. Arch Virol 126: 215-229.

Behan PO, Behan WHM (1988). Postviral fatigue syndrome. CRC Crit Rev Neurobiol 4: 157-178. abnormal transcription was fundamental to this. Similar results with the abnormal production of equal amounts of positive and negative strands of enteroviral RNA (Cunningham et al, 1990) were reported after a study of muscle biopsies from four patients with the chronic fatigue syndrome, a disorder in which enterovirus persistence has also been suggested (Archard et al, 1988; Gow et al, 1991)

We looked for the same phenomenon in this in vitro model. Using a parallel complementary RTPCR assay and in situ hybridisation, however, we found that the ratio of positive to negative viral strands was clearly asymmetrical in the in situ and PCR tests, similar to that found in an acute lytic infection and in contrast to the above findings.

There results also illustrate the problems of defining enteroviral persistence in that there may be different patterns of infection, e.g. productive and 'latent'. There has been an implicit assumption that they are the same but this may not be the case and the opposing views have been ably debated recently (Melchers et al, 1994; Muir and Archard, 1994). It has been suggested that abnormal transcription is fundamental to the establishment of persistence but we have shown that transcription was normal in our in vitro model, indicating that mutations which result in reduced viral multiplication and cytopathogenicity, are not necessarily associated with abnormal transcription. Other viral and host factors have to be taken into account in diseases due to persistent enteroviral infection since it may be that enteroviruses have evolved more than one mechanism of persistence.

\section{Acknowledgements}

We are very grateful to the Barclay Research Trust of Glasgow University for support, and to the McFeat Bequest, the Glasgow Neurosciences Foundation and the Linbury Trust for additional help. We also thank F McGarry for expert technical assistance.
Behan WHM, Behan PO (1993). The role of viral infection in polymyositis, dermatomyositis and chronic fatigue syndrome. Chapter 7. In: Inflammatory Myopathies. FL Mastaglia (ed) Bailliere's Clinical Neurology, Vol 2, No 3, Bailliere Tindall: London, Philadelphia, pp 637-658. 
Borzakian S, Couderc T, Barbier Y, et al (1992). Persistent poliovirus infection: establisment and maintenance involve distinct mechanisms. Virology 186: $398-408$.

Bowles NE, Olsen EGJ, Richardson PJ, Archard LC (1986). Detection of coxsackie-B-virus specific RNA sequences in myocardial biopsy samples from patients with myocarditis and dilated cardiomyopathy. Lancet 1: $1120-1123$.

Bowles NE, Sewry CA, Dubowitz V, Archard LC (1987). Dermatomyositis, polymyositis and coxsackie B virus infection. Lancet 1: 1004-1007.

Cash E, Chamorro M, Brahic M (1988). Minus-strand RNA synthesis in the spinal cord of mice persistently infected with Theiler's virus. J Virol 62: 1824-1826.

Cash P (1991). The application of two-dimensional polyacrylamide gel electrophoresis to medical microbiology: molecular epidemiology of viruses and bacteria. Electrophoresis 12: 592-604.

Chomczynski P, Sacchi N (1987). Single step method of RNA isolation by acid guanidium thiocyanate phenol chloroform extraction. Anal Biochem 162: 156-159.

Cunningham L, Bowles NE, Love RJM, Dubowitz V, Archard LC (1990). Persistence of enteroviral RNA in chronic fatigue syndrome is associated with the abnormal production of equal amounts of positive and negative strands of enteroviral RNA. J Gen Virol 71: $1399-1402$.

Dalakas MC (1995). Enteroviruses and human neuromuscular diseases. Chapter 16. In: Human Enterovirus Infections. Harley A Rotbart (ed). ASM Press: Washington, USA, pp. 387-398.

Davis LE, Bodian D, Price D (1977). Chronic progressive poliomyelitis secondary to vaccination of an immunodeficient child. N Eng J Med 297: 2541-2545.

Evans D, Dunn G, Minor P, Schild G, Conn A, et al (1985). Increased neurovirulence associated with a single nucleotide change in a non-coding region of the Sabian type 3 poliovirus genome. Nature (London) 314: $548-544$.

Farquharson M, Harvie R, McNicol AM (1990). Detection of messenger RNA using a digoxigenin end labelled oligodeoxynucleotide probe. J Clin Pathol 43: 424428.

Gow JW, Behan WMH, Clements GB, Woodall C, Riding M, Behan PO (1991). Enteroviral RNA sequences detected by polymerase chain reaction in muscle of patients with postviral fatigue syndrome. $\mathrm{Br}$ Med $J$ 302: $692-696$.

Gow JW, Cash P, Behan WMH, McGarry F, Simpson K, Behan P (1995). Detection of picornavirus genomic and template RNA strands by a novel semi-nested PCR technique and agarose gel electrophoresis. Electrophoresis 16: $338-340$.

Hillan KJ (1990). Detection of mRNA in fixed tissues using RNA probes. In: Nonradioactive Labelling and Detection of Biomolecules. C Kessler (ed). SpringerVerlag, pp 363-367.

Hohenadl C, Klingel K, Mertsching J, Hofschneider PH, Kandolf R (1991). Strand-specific detection of enteroviral RNA in myocardial tissue by in situ hybridisation. Mol Cell Probes 5: 11-20.

Jarousse N, Fiette L, Grant RA, Hogle JM, McAllister A, Michiels $\mathrm{T}$ et al (1994). Chimeric Theiler's virus with altered tropism for the central nervous system. J Virol 68: $2781-2786$
Kandolf R, Hofschneider PH (1989). Viral Heart Disease. Springer Sem Immunpathol 11: 1-13.

Kandolf R, Klingel K, Mertsching H, Canu A et al (1991). Molecular studies on enteroviral heart disease: patterns of acute and persistent infections. Europ Heart J 12: (Suppl. D) 49-55.

Klingel K, Hohenadl C, Canu A, Albrecht M et al (1992). Ongoing enterovirus-induced myocarditis is associated with persistent heart muscle infection: quantitative analysis of virus replication, tissue damage and inflammation. Proc Nat Acad Sci USA 89: 314-318.

Lipkin IW, Battenberg ELF, Bloom FE, Olstone MBA (1988). Viral infection of neurones can depress neurotransmitter mRNA levels without histologic injury. Brain Res 451: 333-339.

Martino TA, Liu P, Petric M, Sole MJ (1995). Enteroviral myocarditis and dilated cardio-myopathy: a review of clinical and experimental studies. In: Human Enterovirus Infections. HA Rotbert (ed). ASM Press: Washington DC, pp 291-352.

Martyn CN, Barker DJ, Osmond C (1988). Motorneuron disease and past poliomyelitis in England and Wales. Lancet 1: 1319-1322.

Matloubian M, Somasundaram T, Kolhekar SR, Selvakumar R, Ahmed R (1990). Genetic basis of viral persistence: single amino acid change in the viral glycoprotein affects ability of lymphocytic choriomenigitis virus to persist in adult mice. J Exp Med 172: $1043-1048$.

McAllister RM, Melnyk J, Finkelstein JZ, Adams EC, Gardner MB (1969). Cultivation in vitro of cells derived from a malignant human rhabdomyosarcoma. Cancer 24: 520-526.

McKinney RE Jr, Katz SL, Wilfert CM (1987). Chronic enteroviral meningoencephalitis in agammaglobulinaemic patients. Rev Infect Dis 9: $334-356$.

McLaren J, Argo E, Cash P (1993). Evolution of coxsackie $B$ virus during in vitro persistent infection: detection of protein mutations using two-dimensional polyacrylamide gel electrophoresis. Electrophoresis 14: $137-147$

Melchers W, Zoll J, van Kuppeveld F, Swanink C, Galama J (1994). There is no evidence for persistent enterovirus infections in chronic medical conditions in humans. Rev Med Virol 4: 235-243.

Muir P, Archard LC (1994). There is evidence for persistent enterovirus infections in chronic medical conditions in humans. Rev Med Virol 4: 245-250.

Oldstone MBA (1991). Molecular anatomy of viral persistence. I Virol 65: 6381-6396.

Oldstone MBA, Sinha YN, Blount P, Tishon A, Rodriguez M, Wedel R et al (1982). Virus induced alterations in homeostasis: alterations in differentiated functions of infected cells in vivo. Science 218: $1125-1127$

Patick AK, Oleszak EL, Leibowitz JL, Rodriguez M (1990). Persistent infection of a glioma cell line generates a Theiler's virus variant which fails to induce demyelinating disease in SJL/J mice. J Gen Virol 71: $2122-2132$.

Pelletier I, Couderc T, Borzakian S et al (1991). Characterisation of persistent poliovirus mutants selected in human neuroblastoma cells. Virology 180: $729-737$. 
Salvato M, Borrow P, Shimomaye E, Oldstone MA (1991). Molecular basis of viral persistence: a single amino acid change in the glycoprotein of lymphocytic choriomeningitis virus is associated with suppression of the antiviral cytotoxic T-lymphocyte response and establishment of persistence. J Virol 65: 1863-1869.

Schnurr DP, Schmidt NJ (1989). Persistent infections. In: Coxsackie Viruses, a General Update. Bendinelli M, Friedman H (eds). Plenum: New York, pp 181-201.

Sharief MK, Hentges R, Ciardi M (1991). Intrathecal immune response in patients with the post-polio syndrome. New Engl J Med 324: 1206-1207.

Tracy S (1988). The genome of the Group B coxsackieviruses. Chapter 2. In: Coxsackie viruses a general update. Mauro Bendinelli, Herman Friedman (eds). Plenum Publishing Corporation: New York, pp 19-33.

Tracy S, Chapman NM, McManus BM, Pallansch WA, Beck MA et al (1990). A molecular and serologic evaluation of enteroviral involvement in human myocarditis. J Mol Cell Cardiol 22: 403-414.
Webster AD, Rotbart HA, Warner $\mathrm{T}$ et al (1993). Diagnosis of enterovirus brain disease in hypogammaglobulinemic patients by polymerase chain reaction. Clin Infect Dis 17: 657-661.

Wilfert CM, Buckley RH, Mohanakumar T, Griffith SL et al (1977). Persistent and fatal central nervous system echovirus infections in patients with agammaglobulinaemia. $N$ Engl J Med 296: 1485.

Woodall CJ, Riding MH, Graham DI, Clemens GB (1994). Sequences specific for entero-viruses detected in spinal cord from patients with motor neuron disease. Br Med J 308: 1341-1343.

Woodruff JF (1980). Viral myocarditis. Am J Pathol 101: $426-483$.

Zoll GJ, Melchers WJG, Kopecka H, Jambroes G et al (1992). General primer-mediated polymerase chain reaction for detection of enteroviruses: application for diagnostic routine and persistent infections. J Clin Microbiol 30: 160-165. 